Note

\title{
The Tuition Pentagon: students choose an option within a course which matches their motivation, competence and ambition
}

\author{
Michiel van der Ven ${ }^{1}$, Martin de Boer ${ }^{2}$, Jonathan Marty ${ }^{3}$
}

1. HU University of Applied Sciences Utrecht, Business School, Utrecht, The Netherlands, michiel.vanderven@hu.nl

2. HU University of Applied Sciences Utrecht, Business School, Utrecht, The Netherlands, martin.deboer@hu.nl

3. HU University of Applied Sciences Utrecht, Business School, Utrecht, The Netherlands

Received: 30 January 2017; Accepted: 13 March 2017; Published: 2 May 2017

Keywords: honours, student engagement, personalized learning, student types

\section{Introduction}

In redesigning its curriculum and learning environment, the HU Business School focuses on improving student engagement. In its turn, this should improve the academic success rates. Moreover, challenging honours students in regular courses is also an aim of the redesign.

With this in mind, we developed a pilot course in which students are offered five different options of coaching and tuition from the lecturer. This approach was called "The tuition Pentagon". The five options are designed to match different levels of motivation, competence and ambition. Students reflect on their motivation, competence and ambition and choose their preferred option. An option with extra assignments offers a challenge for honours students.

\section{Method}

In order to understand the differences in motivation, ambition, needs, study attitudes and study behaviour of our students, we developed a motivational and social segmentation model (De Boer, Kamphuis \& van der Veen, 2016). This model is used for the design and evaluation of the courses in which students choose from the five options of tuition offered.

Over a period of three years, we run a pilot course. The pilot developed over time. About 300 students were involved. The pilot course (Accounting Information Systems) offered the following five options to choose from:

1. self-study: no classes, only study at home;

2. crash course: consisting of one kick-off lecture, exam preparation and a question hour for the exam of the course, so in total three lectures;

3. regular course: students attend the lectures every week for seven weeks, plus the question hour mentioned above; 
4. regular course with additional individual diagnostic tests and additional counselling; 5. regular course with additional individual diagnostic tests, additional group assignments and additional counselling

All students make the same written exam.

Ad 1 and 2. The options self-study and crash course are suited for students who want to follow the course with minimal class attendance. This may be because of time-limitations due to other study- and private activities, high competence level, or because their interest in the subject is low. It requires good planning skills and self-discipline to be successful.

Ad 3. This option is suited for students with modest motivation, ambition or planning skills.

Ad 4. This option with individual diagnostic tests and counselling is attractive for students with an active study attitude who want to do well and feel the need for extra support and structure.

Ad 5. The option with group assignments is attractive for students who are intrinsically interested in the subject and who are challenged by an extra assignment and intend to perform well.

In order to enable students to make the right choice and to create tutor insight in what drives his students, at the start of the course students are asked to indicate their professional aim in life and their business experience in the subject of the course. Additionally they are asked to explain their motivation for the course and their study attitude and discipline. On the basis of this reflection, each student chooses one of the five options. Then teams are composed of students who choose the same option.

At the end of each lecture, feedback is asked and if possible implemented directly in the next lecture. In this way, the tutor gains trust resulting in open feedback which gives him profound additional insight in student preferences.

\section{Conclusion}

The effectiveness of this pilot is evaluated by assessing the type of student (according to our segmentation model) and the option he has chosen, his study attitude, behaviour during the course, pass rates and student evaluations.

Preliminary results indicate that the exam pass rates have risen from $30 \%$ to $70 \%$ compared to classes that followed the regular course. Exam pass results increased from 6 to 7 out of 10. Not surprisingly, the best exam grades are obtained by the students that choose option 5.

Another important observation is that students experience less negative peer pressure in the classroom from students who can be qualified as "cinema-goers": the cinema-goer sits in the back of the classroom with an attitude "make it a nice time for me and then I'll decide what I think of it". Firstly, their number, and hence their influence, decreases because a part of them chooses self-study or crash course. Secondly, the tutor confronts these students with 
their own choice "not to actively make one". In the realization that it is their own choice to be a cinema-goer, which by no means is a compliment, they start behaving in a more modest way, and that helps. Students who do not opt for the regular course, show more commitment and persistence.

Last but not least this approach offers a challenge for honours students within the standard curriculum.

\section{Discussion}

The ultimate challenge for the tutor is to engage all students by offering them the right didactic approach in order to make them experience autonomy and the possibility to work on their own intrinsic goals. This will increase engagement, persistence and academic success rates (Vansteenkiste et al., 2004).

After the pilot other tutors became involved. New tuition experiments offer either differentiation within classes (as explained above) or, as a new development, between classes (for instance a regular class and a motivation-plus class). These new experiments are currently systematically executed and evaluated.

\section{References}

De Boer, M.J.M., Kamphuis, A. \& van der Veen, G. (2016). Working with student personas: engaging students through personalized education. Presentation at the EDINEB conference, Nice, June 8-10, 2016.

Vansteenkiste, M., Simons, J., Lens, W., Sheldon, K.M. \& Deci, E.L. (2004). Motivating learning, performance and persistence: the synergistic effects of intrinsic goal contents and autonomy-supportive contexts. Journal of Personality and Social Psychology, 87, 246-260 